\title{
Eozinofilia - factor trigger pentru tromboza venoasă profundă şi embolia pulmonară la un pacient cu trombofilie
}

\author{
Marilena Constantin' ${ }^{1}$ Gabriel Zamfirescu' ${ }^{1}$, Cristina Voinea' ${ }^{1}$, Sorin Constantinescu ${ }^{1}$ \\ Fundația „Victor Babeş", Bucureşti, România
}

\begin{abstract}
REZUMAT
Introducere. Infiltratele pulmonare şi eozinofilia reprezintă un grup heterogen de afecţiuni determinate de factori intrinseci si extrinseci. Factorii extrinseci reprezentaţi de medicaţie sau agenţi infecţioşi declanşează un răspuns eozinofilic imun. Raportăm cazul unui pacient de 53 ani, bărbat, cu infiltrat pulmonar si eozinofilie, secundare infecţiei cu Toxocara canis, care a fost diagnosticat cu tromboză venoasă profundă şi embolie pulmonară la o lună de la diagnosticul infecţiei cu Toxocara canis. Investigaţiile ulterioare au arătat prezenţa statusului procoagulant.

Prezentarea cazului. În martie 2015, pacientul, în vârstă de 53 ani, s-a prezentat la consultaţie pentru durere intensă la nivelul toracelui posterior accentuată de inspir profund. Examenul clinic a fost în limite normale, dar tomografia computerizată fără substanţă de contrast efectuată în urgenţă a arătat infiltrat pulmonar la baza plămânului stâng cu reacţie pleurală. Analizele de sânge au indicat leucocite la limita superioară, eozinofilie $\left(21,5 \%, 2.050 / \mathrm{mm}^{3}\right)$ şi sindrom inflamator. Investigaţiile pentru eozinofilie au arătat reacţie pozitivă pentru Toxocara canis. Se începe tratamentul cu Albendazol 800 mg/zi cu răspuns favorabil. La interval de o lună, pacientul se prezintă pentru durere la nivelul gambei drepte. Testul pentru D-Dimer a fost intens pozitiv, ecografia Doppler venos confirmă diagnosticul de tromboză venoasă profundă, iar tomografia computerizată cu substanţă de contrast a descris embolie pulmonară. Pacientul a început tratamentul anticoagulant. A efectuat analizele de trombofilie care au fost pozitive pentru MTHFR A 1298C homozigot şi gena PAI1 675. Discuţii. Infecţiile cu helminţi se asociază cu eozinofilie. Helminţii care migrează spre viscere, cum este şi cazul Toxocarei canis, produc răspuns eozinofilic înalt. Întrebarea la care am încercat să răspundem a fost dacă eozinofilia a fost responsabilă pentru tromboze sau a reprezentat doar un factor de risc. Întrucât două teste genetice pentru trombofilie au fost pozitive (MTHFR A 1298C homozigot şi gena PAl1 675), s-a considerat apariţia trombozei venoase şi a emboliei pulmonare în contextul statusului procoagulant al pacientului. Concluzii. Acest caz clinic subliniază implicarea eozinofiliei ca factor trigger pentru embolia pulmonară şi tromboza venoasă profundă.
\end{abstract}

Cuvinte cheie: eozinofilie, tromboză venoasă, infecție cu Toxocara canis

\section{INTRODUCERE}

Infiltratele pulmonare şi eozinofilia reprezintă un grup heterogen de afecţiuni determinate de factori intrinseci si extrinseci. Factorii extrinseci reprezentaţi de medicaţie sau agenţi infecţioşi declanşează un răspuns eozinofilic imun. Raportăm cazul unui pacient de 53 ani, bărbat, cu infiltrat pulmonar si eozinofilie secundare infecţiei cu Toxocara canis, care a fost diagnosticat cu tromboză venoasă profundă şi embolie pulmonară la o lună de la inţierea tratamentului pt. toxocarioză. Investigaţiile ulterioare au arătat prezența statusului procoagulant.

\section{PREZENTAREA CAZULUI}

În martie 2015, un pacient în vârstă de 53 ani, de sex masculin, se prezintă la consultaţie pentru durere toracică posterioară intensă accentuată de inspirul profund. Examenul clinic a descris pacient normoponderal, cu examen pulmonar în limite normale, fară febră, $\mathrm{TA}=120 / 70 \mathrm{mmHg}, \mathrm{AV}=75 /$ min, ritmic.

Analizele de sânge au arătat leucocite la limita superioară a normalului cu hipereozinofilie $(21,7 \%$, $2.050 / \mathrm{mm}^{3}$ ) şi sindrom inflamator $(\mathrm{VSH}=16$ $\mathrm{mm} / \mathrm{h}, \mathrm{CRP}=5,24 \mathrm{mg} / \mathrm{dl}$, fibrinogen $536 \mathrm{mg} / \mathrm{dl}$ ). Tomografia computerizată fără contrast, efectuată 
în urgenţă, a descris infiltrat pulmonar la baza toracelui stâng cu reacţie pleurală.

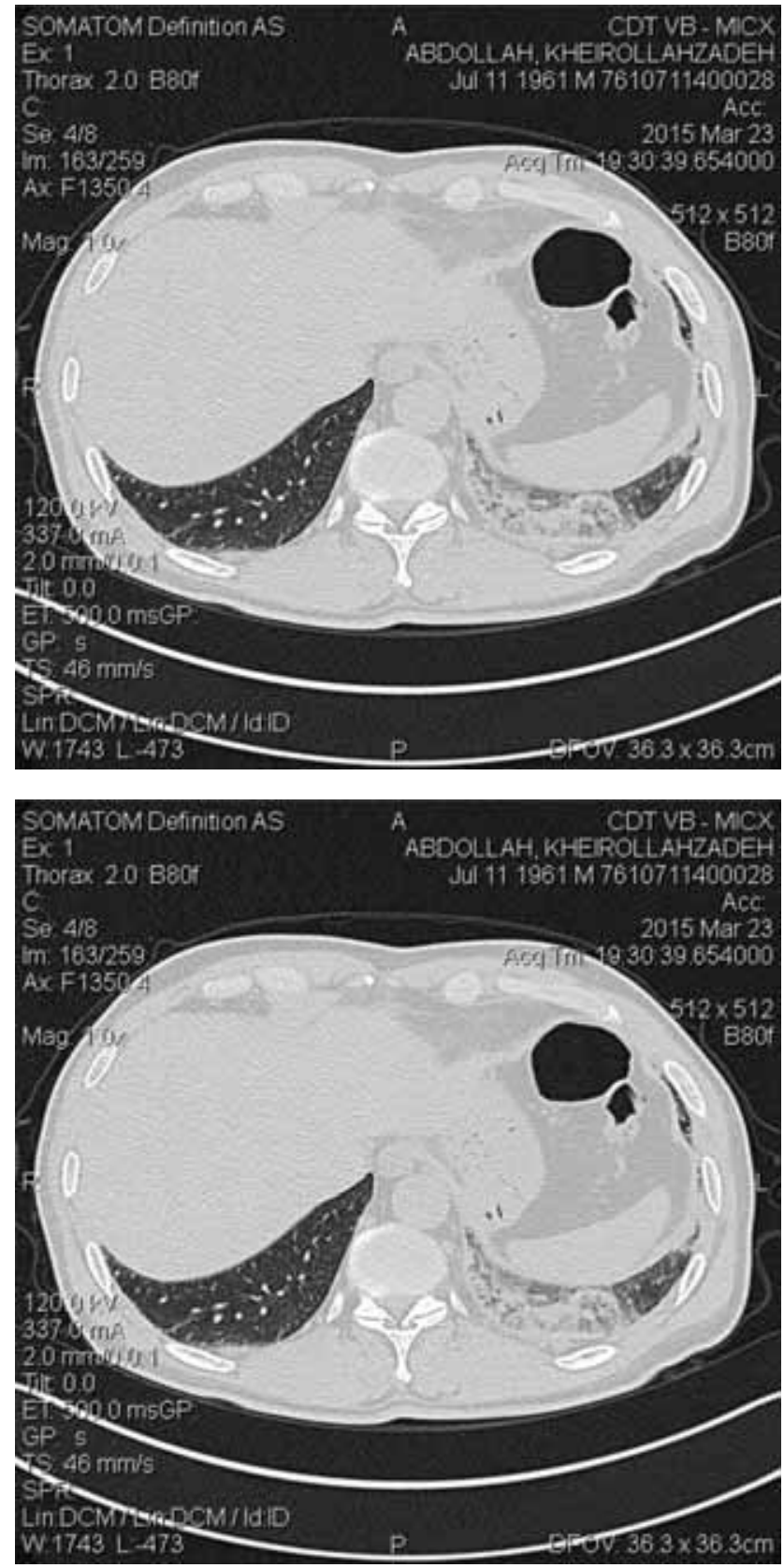

FIGURA 1. Infiltrat pulmonar stâng

S-a recomandat bronhoscopie cu lavaj, dar pacientul a refuzat. S-a iniţiat tratament antibiotic (chinolone) şi s-a investigat eozinofilia. Întrucât testul Western Blot pentru Toxocara canis a fost pozitiv, s-a început tratamentul cu Albendazol 800 mg/zi timp de 3 săptămâni, cu răspuns favorabil la tratament. Examenul oftalmologic, efectuat în aprilie 2015, a fost normal.

În aprilie 2015, pacientul se prezintă pentru o nouă consultaţie cu durere la nivelul gambei drepte. Testul pentru D-Dimer a fost intens pozitiv, iar ecografia Doppler vene membre inferioare a descris tromboză venoasă profundă. Pacientul a fost internat, iar tomografia computerizată cu substanţă de contrast a descris embolie pulmonară dreaptă. S-a început tratamentul anticoagulant.

Pacientul a repetat tomografia computerizată în mai 2015. S-au constatat rezoluţia emboliei pulmonare, absenţa infiltratului pulmonar stâng, prezenţa unor leziuni de fibroză la nivelul plămânului stâng.
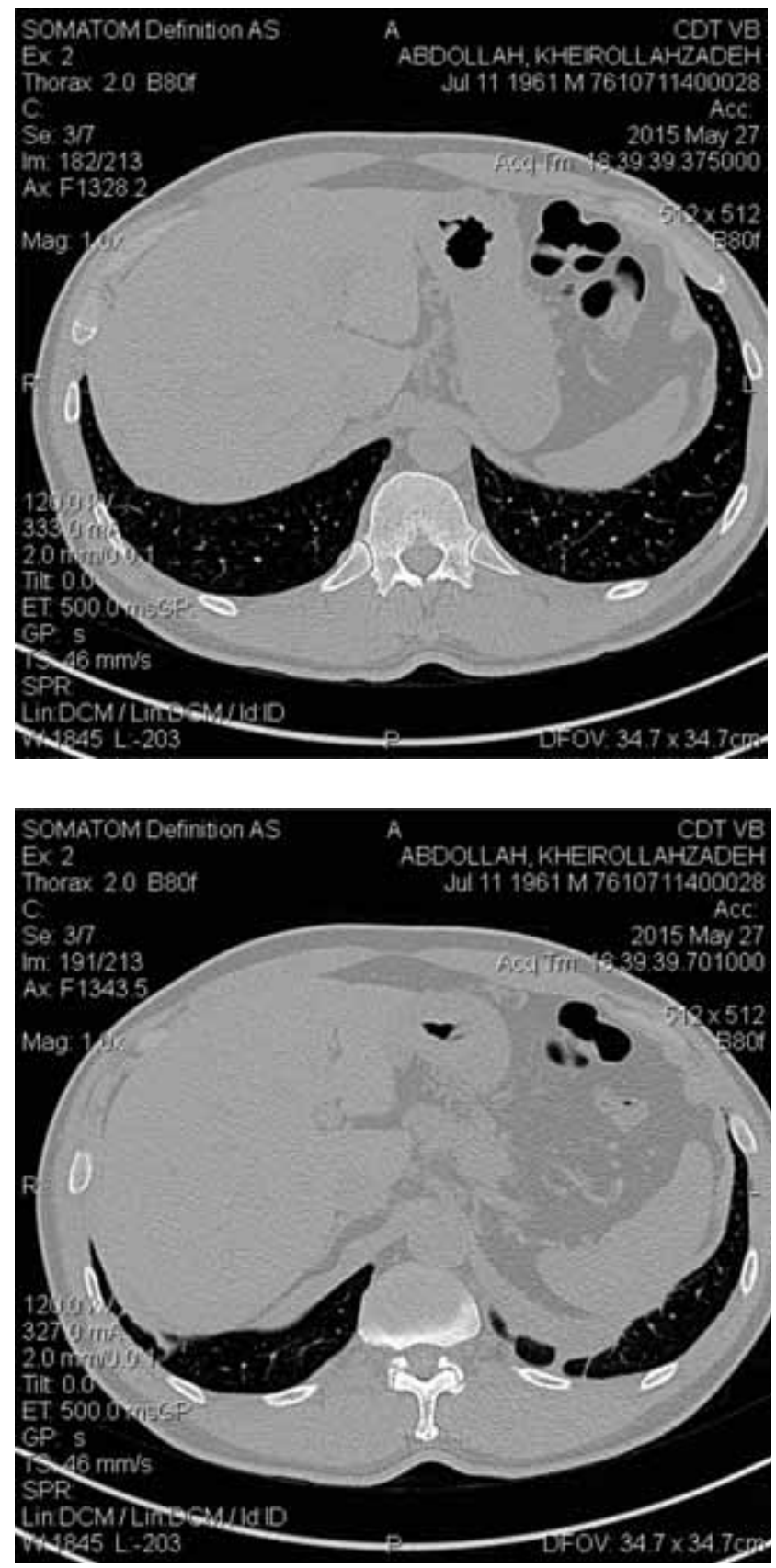

FIGURA 2. Rezoluția infiltratului pulmonar

Ecografia Doppler de vene membre inferioare a fost nemodificată faţă de precedenta.

Consultul de hematologie şi analizele de trombofilie au arătat prezenţa mutaţiilor genetice MTHFR şi PAI1 675. 


\section{DIAGNOSTIC}

\section{Toxocarioză}

\section{Embolie pulmonară}

Tromboză venoasă profundă femuropoplitee

\section{dreaptă}

Trombofilie

TABELUL 1. Istoric caz

\begin{tabular}{|c|c|}
\hline DATA & ANALIZE/INVESTIGATII \\
\hline 24 Mar e & $\begin{array}{l}\mathrm{Hb}=15,8 \mathrm{~g} / \mathrm{dl} ; \mathrm{Ht}=46,6 \% ; \mathrm{L}=9.460 / \mathrm{mm}^{3} ; \\
\text { eO= } 21,7 \%(2.050 / \mathrm{mcl}) ; \mathrm{T}=232,000 / \mathrm{mm}^{3} ; \\
\mathrm{VSH}=16 \mathrm{~mm} / \mathrm{h} ; \mathrm{fib}=536 \mathrm{mg} / \mathrm{dl} ; \\
\mathrm{CRP}=5,24 \mathrm{mg} / \mathrm{dl} \\
\text { CT torace na v: infiltrat posterobazal plămân stâng } \\
\text { cu reacţie pleurală și scizurită stângă }\end{array}$ \\
\hline 03 Aprilie & $\begin{array}{l}\text { Spirometrie normal } \\
\text { IgE > } 500 \text { ui/ml; WB Toxocara canis pozi v; } \\
\text { WB Fasciola hepa ca nega } v\end{array}$ \\
\hline 05 Aprilie & $\begin{array}{l}\text { Ecocardiografie: normal } \\
\text { An Toxoplasma IgM nega v; } \\
\text { an Toxoplasma IgG posi v }\end{array}$ \\
\hline 06 Aprilie & $\begin{array}{l}\mathrm{Hb}=15,6 \mathrm{~g} / \mathrm{dl} ; \mathrm{Ht}=45,6 \% ; \mathrm{L}=8.400 / \mathrm{mm}^{3} ; \\
\mathrm{Eo}=19 \%\left(1.600 / \mathrm{mm}^{3}\right) ; \\
\mathrm{T}=253.000 / \mathrm{mm}^{3} ; \mathrm{CRP}=0,8 \mathrm{mg} / \mathrm{dl} \\
\text { HIV nega v; an Aspergillus nega v } \\
\text { uree, crea nină normal }\end{array}$ \\
\hline 21 Aprilie & $\begin{array}{l}\text { Ex. pneumologie: Pneumonie stângă cu eozinofilie. } \\
\text { Toxocaroză. } \\
\text { Recomandare: bronhoscopie cu lavaj }\end{array}$ \\
\hline 29 Aprilie & $\begin{array}{l}\text { D-dimer }=4.778 \mathrm{ng} / \mathrm{ml} \text { pozi vi } \\
\text { Spitalizare: Embolie pulmonară.Tromboză venoasă } \\
\text { profundă dreaptă. Varice membre inferioare. } \\
\text { Toxocaroză. Gastrită cronică. } \\
\text { CT torace cu contrast: embolie pulmonară dreaptă } \\
\text { Recomandări: tratament an coagulant }\end{array}$ \\
\hline $08 \mathrm{Mai}$ & $\begin{array}{l}\mathrm{L}=6.750 / \mathrm{mm}^{3} ; \text { eo }=6,1 \%(416 / \mathrm{mcl}) ; \\
\mathrm{Hb}=14,5 \mathrm{~g} / \mathrm{dl} ; \mathrm{Ht}=42 \% ; \mathrm{T}=284.000 / \mathrm{mm}^{3} ; \\
\text { D-dimer }=1.117 \mathrm{ng} / \mathrm{ml} ;\end{array}$ \\
\hline 12 Mai & $\begin{array}{l}\text { Fct. V Leiden nega v; fct II G } 20210 \text { A nega v; } \\
\text { homozigot pozi v genele } \\
\text { MTHFR A 1298C homozigot și gena PAI1 } 675 .\end{array}$ \\
\hline $21 \mathrm{Mai}$ & D-dimer $342 \mathrm{ng} / \mathrm{ml}$ \\
\hline $26 \mathrm{Mai}$ & $\begin{array}{l}\text { Ecografie Doppler vene membre inferioare: } \\
\text { Tromboză venoasă profundă venă femuropoplitee } \\
\text { dreaptă }\end{array}$ \\
\hline 27 Mai & $\begin{array}{l}\text { Rezoluţia emboliei pulmonare; modificări de } \\
\text { fibroză posterobazal plămân stâng. }\end{array}$ \\
\hline
\end{tabular}

\section{DISCUŢII}

Infiltratele pulmonare asociate $\mathrm{cu}$ eozinofilie sunt descrise în literatură pentru un grup heterogen de afecţiuni determinate de factori extriseci şi intrinseci.

\section{Cauze de infiltrate pulmonare cu eozinofilie} (1)

\section{Idiopatice:}

- sindrom Loffler

- eozinofilia pulmonară (acută, cronică)

- sindrom hipereozinofilic idiopatic
Secundare:

- medicamentoase (expunere la iod, aspirina, sulfamidele, nitrofurantoin, peniciline, cefalosporine)

- infecțioase (fungice, parazitare: schistosomiaza 50\%, ascarizii, Toxocara canis)

- aspergiloza bronhopulmonară alergică

- bolile vasculare de colagen

- tumori

Vasculite eozinofilice

- sindrom Churg-Strauss

Studiul literaturii de specialitate a evidenţiat ipoteze (3) care ar putea explica relaţia eozinofilietromboze. În primul rând, eozinofilul eliberează factori eozinofilici: proteina bazică majoră (MBP) care afectează stratul lipidic al membranei celulare, creşte permeabilitatea acesteia, induce leziuni endoteliale; peroxidaza eozinofilică (EPO) are efect citotoxic; proteina cationică eozinofilică (ECP) induce leziune endotelială; factorul de activare plachetar induce activarea plachetelor. În al doilea rând, eozinofilele stochează şi exprimă pe suprafaţă factori tisulari. În al treilea rând, eozinofilele exprimă ligandul CD40, implicat în iniţierea şi progresia trombozei.

În infecţiile cu helminţi, eozinofilia poate atinge niveluri foarte mari ca răspuns al organismului gazdă, în special pentru helminţii care migrează spre viscere.

În cazul prezentat, eozinofilia a fost indusă de infecţia cu Toxocara canis. Nu ştim exact cum a contactat pacientul această infecție, dar, deși locuieşte în mediu urban, se deplasează periodic în mediu rural.

Prevalenţa globală a infecţiei cu Toxocara canis nu este cunoscută, dar creşte la peste $40 \%$ în unele ţări (CDC). Este mai ridicată în comunitatea rurală. Toxocara canis infectează căţeii. În intestinul subţire, oul de parazit eliberează larva care migrează spre ficat, plămân, trahee. Manifestările clinice pentru larva migrans visceralis implică plămânul (32-44\%), ficatul şi splina. Manifestările neurologice şi afectarea oculară sunt rare (2).

Diagnosticul se confirmă prin testul ELISA (IgM) (2).

Particularitatea cazului este reprezentată de debutul atipic pneumonia like, cu durere toracică intensă şi infiltrat pulmonar descris la tomografia computerizată toracică, fără febră sau tuse. Prezen- 


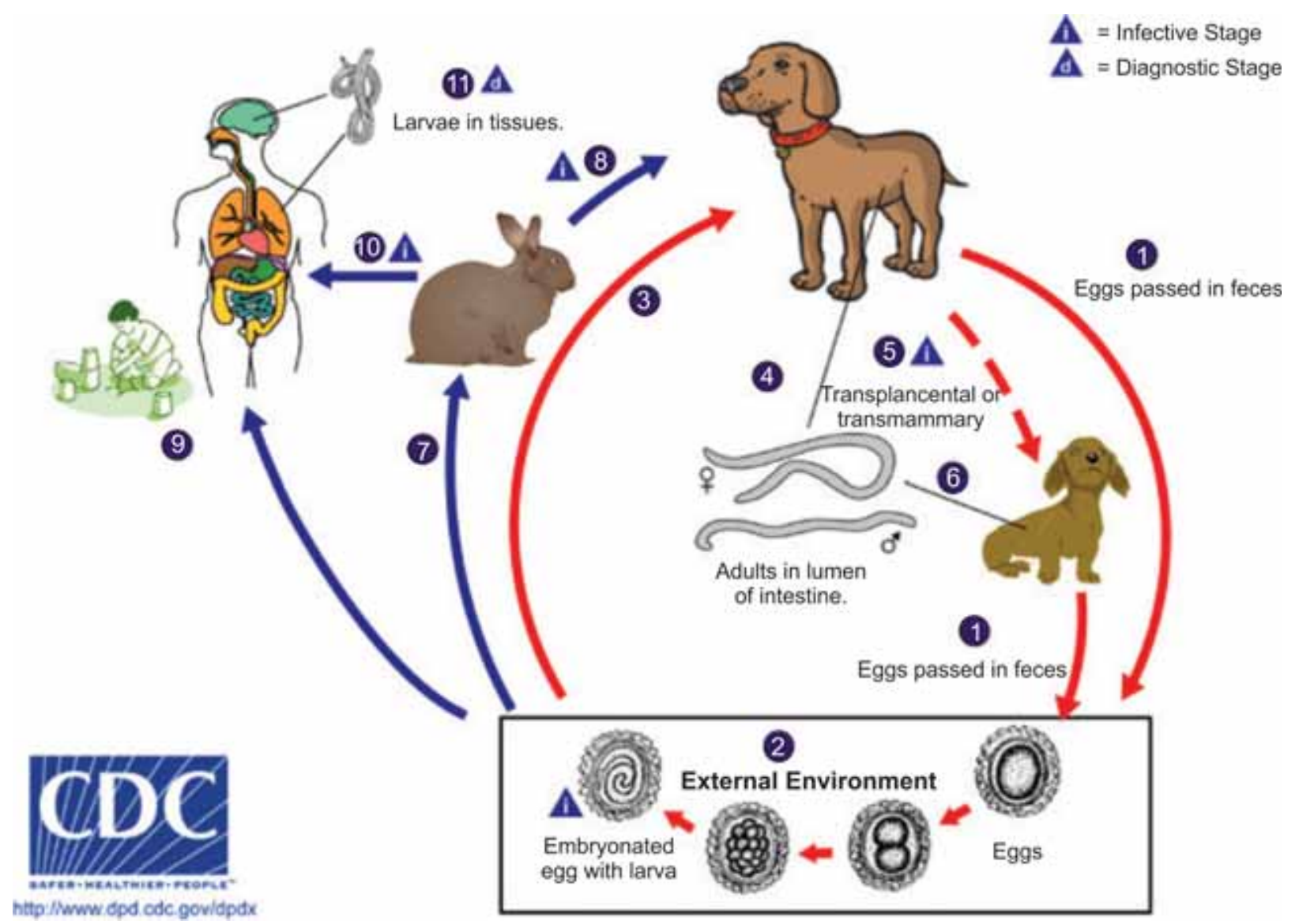

FIGURA 3. Life Cycle

Sursa: Centers for Disease Control and Prevention

ţa eozinofiliei a impus efectuarea analizelor de parazitologie.

Tromboza venoasă profundă şi embolia pulmonară au fost dignosticate în timpul evoluţiei afecţiunii parazitare. Întrebarea pe care ne-am adresat-o a fost dacă eozinofilia a fost responsabilă de apariţia trombozei sau a reprezentat factorul trigger. Întrucât două teste genetice de trombofilie au fost pozitive (MTHFR A 1298C homozigot şi gena PAI1 675), considerăm tromboza în contextul statusului procoagulat al pacientului. Literatura de specialitate (4) descrie implicarea mutaţiilor descrise în creşterea riscului de tromboză venoasă profundă.

\section{EVOLUŢIE}

După tratamentul cu Albendazol, infiltratul pulmonar a dispărut şi s-a constatat scăderea numărului de eozinofile şi a valorilor $\operatorname{IgE}$.
La momentul actual, pacientul este sub tratament anticoagulant cu warfarină (s-a încercat apixaban, dar s-a observat creşterea enzimelor hepatice). Pacientul este clinic normal, cu analize de sânge cu valori normale. Va fi supravegheat în continuare.

\section{CONCLUZII}

Infecţia cu Toxocara canis a indus hipereozinofilie, care a reprezentat factor trigger pentru tromboza venoasă şi embolia pulmonară la un pacient de 53 ani şi a evidenţiat statusul procoagulant al pacientului. 